\title{
ANALYSIS AND EFFECT OF GENERALIZED UNIFIED POWER FLOW CONTROLLER: AN OPTIMAL LOCATION STRATEGY
}

\author{
Chintalapudi V Suresh ${ }^{1}$, Sirigiri Sivanagaraju ${ }^{1}$ \\ Department of Electrical and Electronics Engineering, University College of Engineering, \\ JNTU Kakinada, Kakinada, Andhra Pradesh, India ${ }^{1}$
}

\begin{abstract}
The present technological developments in power electronics industry increase the utilization of various types of Flexible AC Transmission Systems (FACTS) controllers. Depending on the type of converters connection, there are single and multi-line FACTS controllers. Based on the type of connection, amount of the compensation and the advantage of convertible static compensators (CSC), Generalized Unified Power Flow Controller (GUPFC) is presented in this paper. Voltage source based power injection model of GUPFC is used to incorporate this device in Newton Raphson load flow solution, to analyze the effect of this device on system parameters. The proposed methodology is tested on standard IEEE-5 bus and IEEE-14 bus test systems with supporting numerical and graphical results.
\end{abstract}

Keywords: Generalized Unified Power Flow Controller; Optimal location; Voltage source based model; Incorporation procedure

\section{INTRODUCTION}

The basic concept of these FACTS controllers, because of incorporating self commutated semiconductor devices, the power flow can be diverted through some of the specific transmission lines, so as to increase the power transfer capability of the lines to its maximum limits such as thermal as well as voltage stability and security limits to minimize the impact on the environmental conditions. Using these devices, it is possible to control the voltage angle and magnitude at the system buses and the power flow through the transmission lines by varying the transmission line impedance of transmission system.

Based on the type of connection of the converters in a system, these FACTS controllers can be classified as series, shunt, combined series-shunt and combined seriesseries controllers. Similarly, based on the controlling purposes, these are classified as single line power flow controllers and multi-line power flow controllers. The latest convertible static compensators such as interline power flow controllers, generalized unified power flow controllers, etc., are developed to control multiple transmission lines simultaneously.

The Unified Power Flow Controller (UPFC) can be used for simultaneous control of the power system parameters (voltage, impedance, phase angle), or any of the above combinations $[1,2]$ as it is a versatile and effective device. This device consist one series converter coordinated with one shunt converter. An optimal location to install UPFC based on real power flow performance index is given in [3-5]. A steady state model of UPFC in terms of power injections is discussed in [6]. UPFC is a versatile device can control the active power and reactive power independently or simultaneously. Similarly, the voltage magnitude at system buses can also be controlled. A comprehensive load flow model for UPFC, to incorporate into existing Newton-Raphson (NR) Load flow is

presented in [7]. An algorithm is proposed for determining the optimum flow and size of UPFC for power flow applications [8]. A set of analytical equations are derived to control any combination of the power system parameters or none of them [9]. It is possible to study the power flow control in the presence of UPFC by obtaining sensitivity matrix of the power system [10]. The UPFC operation, control, sequencing, and protection methodologies under practical constraints are discussed in [11]. The congestion management in power system is possible with the selection of suitable location and settings of its control parameters [12]. An effective injection modeling approaches to power flow analysis in the presence of UPFC is discussed in [13-15]. Power Injection Model (PIM) of UPFC and its effect, based on location are analyzed in $[16,17]$. Advanced UPFC model to reuse NR Load flow has been developed in [18].

The complete working procedure and fundamental frequency model of GUPFC is described in [19]. A fuzzy rule based model for GUPFC is proposed in [20]. In [21], a mathematical model of the GUPFC suitable for power flow is proposed. Nonlinear predictor-corrector primaldual interior-point optimal power flow algorithm for GUPFC is presented in [22]. Voltage source based mathematical models of the GUPFC and its implementation in Newton power flow is presented in [23]. The design of the GUPFC damping controller is designed in [24]. Analysis of sub synchronous resonance with GUPFC is presented in [25].

From the careful review of the literature, it is identified that, voltage source converter based modelling is easy to model the FACTS controllers to analyse the effect of these controllers on a given system. In this paper, one of the multi-line convertible static compensator popularly known as Generalized Unified Power Flow Controller (GUPFC) 
is modelled using voltage source converter based modelling. The complete incorporation procedure in conventional NR load flow algorithm is also presented. To maximize the effectiveness and obtained maximum benefit out of this device, it should be installed in an optimal location. In this paper, an optimal location of GUPFC is identified through contingency analysis. The effectiveness of the proposed methodology with GUPFC in an optimal location is studied on standard IEEE-5 bus and IEEE-14 bus test systems with supporting graphical and numerical results.

\section{Mathematical MOdelling OF GUPFC}

In general, GUPFC consist three voltage source converters and using this basic configuration, it can control power flow in two transmission lines simultaneously by varying device control parameters. For the sake of explanation, the complete voltage source based mathematical modeling of GUPFC is presented in this section. The principle configuration of GUPFC connected between buses $i, j$ and $\mathrm{k}$ is shown in Fig.1.

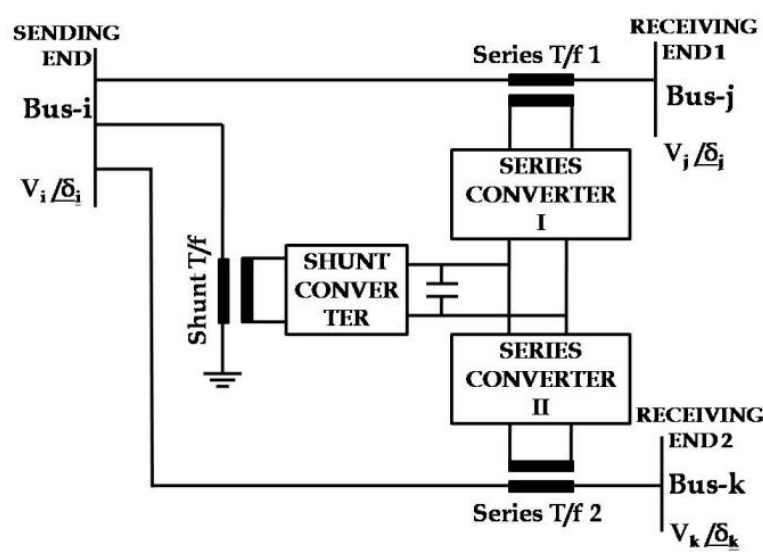

Fig 1. Schematic diagram of GUPFC

In this configuration, two voltage source converters are connected in two different transmission lines having a common bus. The third converter is connected at this common bus and acts as a shunt connected voltage source converter. This shunt converter supplies the power that is supplied by the series converters. All these converters are connected through a common DC link to exchange the power flow.

For the sake of simplification, it is assumed that, the voltage injected by the series converters is sinusoidal and the reactance of the coupling transformer is neglected. With these assumptions, the final voltage source model of GUPFC is shown in Fig.2. The voltages at GUPFC connected buses can be expressed as $\bar{V}_{m}=\left|V_{m}\right| \angle \delta_{m} \quad \forall \quad m=i, j, k$

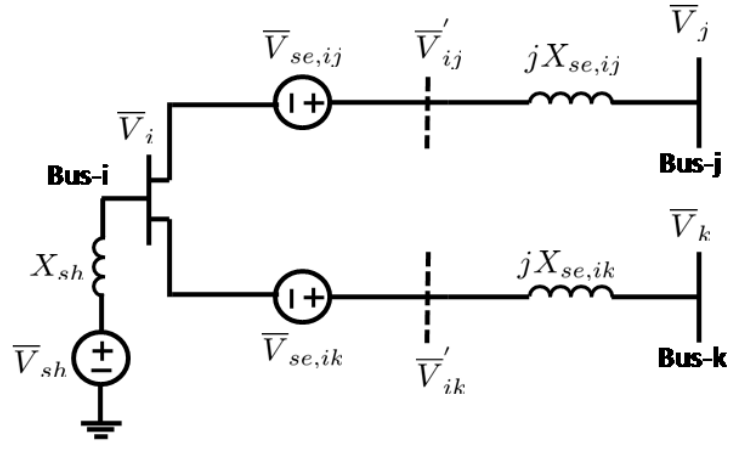

Fig.2. Voltage source model of GUPFC

The voltage injected by the series converters can be expressed as

$\bar{V}_{s e, i m}=\left|V_{\text {se,im }}\right| \angle \delta_{\text {se,im }} \quad \forall \quad m=j, k$

In Fig.2, the voltage behind the series voltage source can be expressed for both converters as

$\bar{V}_{i m}^{\prime}=\bar{V}_{i}+\bar{V}_{s e, i m} \quad \forall m=j, k$

To develop the power injection model, the voltage source model is converted into an equivalent current source model using Norton's theorem and is shown in Fig.3.

$\bar{I}_{s e, i m}=-j B_{s e, i m} \bar{V}_{s e, i m}$

Where, $\quad B_{s e, i m}=\frac{1}{j X_{s e, i m}}$ is the admittance of the coupling transformer.

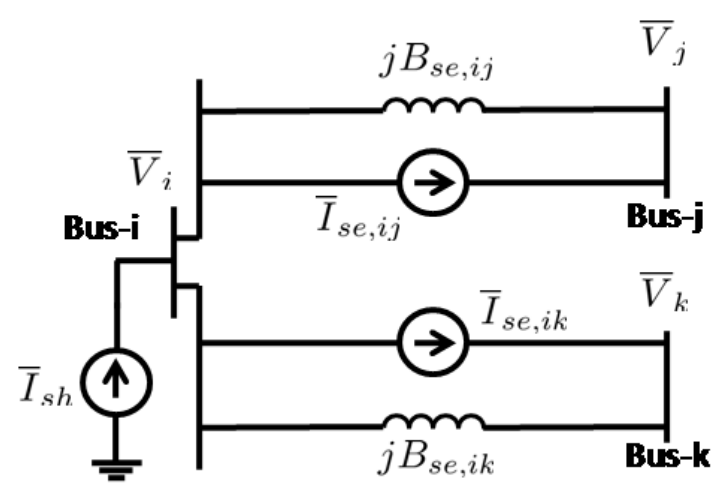

Fig.3. Equivalent current source model GUPFC

Using this, the power injected by these sources at the device connected buses can be expressed as

$\bar{S}_{i, s e}=\bar{V}_{i}\left(-\bar{I}_{s e, i j}-\bar{I}_{s e, i k}\right)^{*}$

$\bar{S}_{m, s e}=\bar{V}_{m} \bar{I}_{s e, i m}^{*}$

Using Eqns. (4), (5) and (6) can be simplified as

$\bar{S}_{i, s e}=\sum_{m=j, k}\left(-j V_{i} V_{s e, i m} B_{s e, i m} \angle\left(\delta_{i}-\theta_{s e, i m}\right)\right)$

$\bar{S}_{m, s e}=j V_{m} V_{s e, i m} B_{s e, i m} \angle\left(\delta_{m}-\theta_{s e, i m}\right) \quad \forall m=j, k$

The final series voltage source with the respective power injections is shown in Fig.4. 


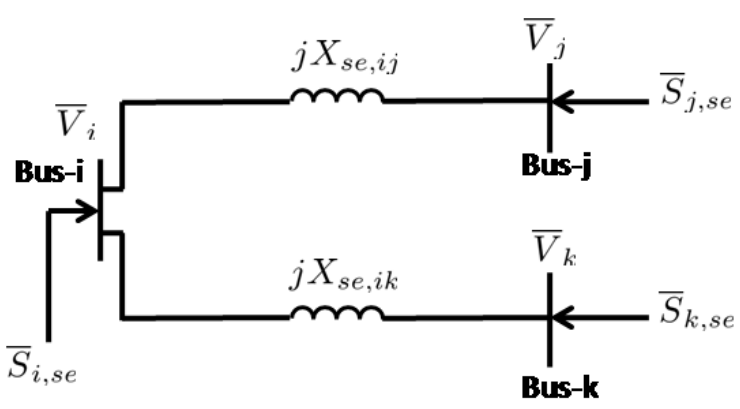

Fig.4. Equivalent series voltage source model of GUPFC

Similarly, the shunt connected voltage source converter can be modeled as an equivalent power injection at the respective bus. In this modeling, it is assumed that, the reactive power injected by the shunt converter is zero, because the purpose of this reactive power is to maintain the voltage magnitude at the converter connected bus. The equivalent shunt voltage source model of GUPFC is shown in Fig.5. The net active power injected at shunt converter connected bus can be expressed as

$P_{\text {sh }}=-P_{\text {series }, i j}-P_{\text {series }, i k}$

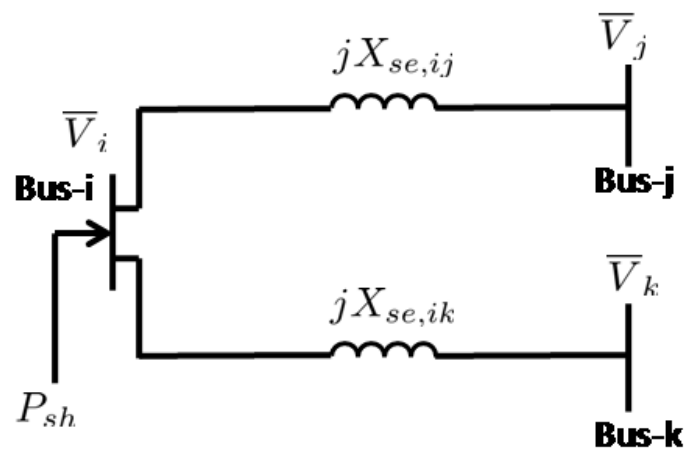

Fig.5. Equivalent shunt voltage source model

The amount of apparent power supplied the series converters can be calculated as

$\bar{S}_{\text {series }, i m}=\bar{V}_{s e, i m} \bar{I}_{i j}^{*}=j \bar{V}_{s e, i m} B_{s e, i m}\left(\bar{V}_{i j}^{\prime}-\bar{V}_{m}\right)^{*}$

Using Eqn (3), after simplifying, the expressions for active and reactive powers supplied by the series converters derived are

$$
\begin{aligned}
& P_{\text {series }, i m}=V_{i} V_{\text {se }, i m} B_{\text {se }, i m} \sin \left(\theta_{\text {se }, i m}-\delta_{i}\right) \\
& -V_{m} V_{s e, i m} B_{s e, i m} \sin \left(\theta_{s e, i m}-\delta_{j}\right) \quad \forall m=j, k \\
& Q_{\text {series }, i m}=-V_{i} V_{\text {se,im }} B_{\text {se }, i m} \cos \left(\theta_{\text {se }, i m}-\delta_{i}\right) \\
& +V_{m} V_{s e, i m} B_{s e, i m} \cos \left(\theta_{s e, i m}-\delta_{j}\right)-V_{s e, i j}^{2} B_{s e, i j} \quad \forall m=j,
\end{aligned}
$$

The final power injection model is obtained by combining series voltage source model and shunt voltage source model. The combined model is shown in Fig.6. The respective power injections at GUPFC connected buses

$$
\begin{aligned}
& \begin{array}{l}
P_{i}^{\text {gupfc }}= \\
\quad-V_{i} V_{s e, i j} B_{s e, i j} \sin \left(\delta_{i}-\theta_{s e, i j}\right)+2 V_{i} V_{s e, i k} B_{s e, i k} \sin \left(\delta_{i}-\theta_{s e}\right. \\
\quad-V_{j} V_{s e, i j} B_{s e, i j} \sin \left(\delta_{j}-\theta_{s e, i j}\right)-V_{k} V_{s e, i k} B_{s e, i k} \sin \left(\delta_{i}-\theta_{s e, t}\right.
\end{array} \\
& P_{j}^{g u p f c}=-V_{j} V_{s e, i j} B_{s e, i j} \sin \left(\delta_{j}-\theta_{s e, i j}\right) \\
& Q_{j}^{\text {gupfc }}=V_{j} V_{s e, i j} B_{s e, i j} \cos \left(\delta_{j}-\theta_{s e, i j}\right) \\
& P_{k}^{\text {gupfc }}=-V_{k} V_{s e, i k} B_{s e, i k} \sin \left(\delta_{k}-\theta_{s e, i k}\right) \\
& Q_{k}^{g u p f c}=V_{k} V_{s e, i k} B_{s e, i k} \cos \left(\delta_{k}-\theta_{s e, i k}\right)
\end{aligned}
$$$$
Q_{i}^{g u p f c}=-V_{i} V_{s e, i j} B_{s e, i j} \cos \left(\delta_{i}-\theta_{s e, i j}\right)-V_{i} V_{s e, i k} B_{s e, i k} \cos \left(\delta_{i}-\theta_{s e, i} H_{j i}^{g u p f c}=\frac{\partial P_{j}^{\text {gupfc }}}{\partial \delta_{i}}=Q_{j}^{\text {gupfc }}\right.
$$

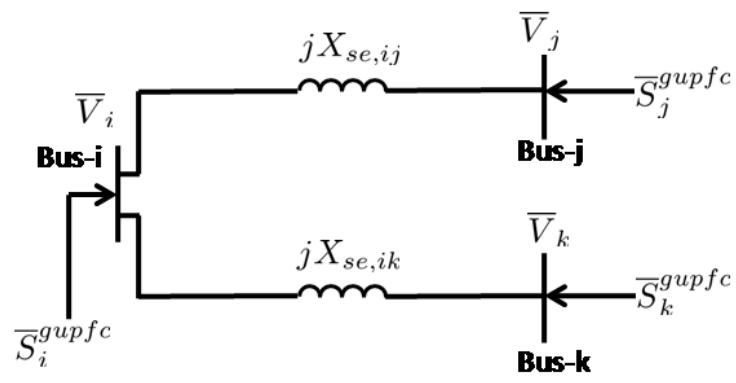

Fig.6. Equivalent power injection model of GUPFC

\section{III.INCORPORATION OF GUPFC MODEL IN NEWTON RAPHSON ALGORITHM}

To incorporate GUPFC in a given network, the conventional system equation in Newton Raphson load solution should modify to show the impact of the device. The developed power injection model is very to incorporate in a given power system by modifying the Jacobian and power mismatch equations at the IPFC connected buses. The final steady state network equation in the presence of this device can be expressed as $\left(\left[\begin{array}{l}\Delta P \\ \Delta Q\end{array}\right]+\left[\begin{array}{l}P^{\text {gupfc }} \\ Q^{\text {gupfc }}\end{array}\right]\right)=\left(\left[\begin{array}{cc}H & N \\ J & L\end{array}\right]+\left[\begin{array}{cc}H^{\text {gupfc }} & N^{\text {gupfc }} \\ J^{\text {gupfc }} & L^{\text {gupfc }}\end{array}\right]\right)\left[\begin{array}{l}\Delta \delta \\ \frac{\Delta V}{V}\end{array}\right]$ Where, $\Delta P, \Delta Q$ are the respective power mismatch vectors, $\Delta \delta, \Delta V$ are the vector increments with respect to voltage magnitude and angles, $H, N, J$, and, $L$ are the partial derivatives with respect to $\delta$ and $V$ respectively.

The respective power mismatch equations and Jacobian elements corresponds to GUPFC connected buses can be represented as

\section{A. Modifications in power mismatch equations}

The power mismatch equations at the GUPFC connected buses can be modified by adding the GUPFC injected powers to the power mismatch equations without device. These power mismatch equations can be expressed as
$\Delta P_{m}^{\text {gupfc }}=\Delta P_{m}^{0}+P_{m}^{\text {gupfc }}$
$\Delta Q_{m}^{\text {gupfc }}=\Delta Q_{m}^{0}+Q_{m}^{\text {gupfc }}$
$\forall m=i, j, k$

B. Modifications in Jacobian elements

The diagonal and off-diagonal elements of ' $H^{g u p f c}$, are $H_{i i}^{g u p f c}=\frac{\partial P_{i}^{g u p f c}}{\partial \delta_{i}}=-Q_{j}^{g u p f c}-Q_{k}^{g u p f c}$

$H_{j j}^{g u p f c}=\frac{\partial P_{j}^{g u p f c}}{\partial \delta_{j}}=-Q_{j}^{g u p f c}$

$H_{k k}^{g u p f c}=\frac{\partial P_{k}^{g u p f c}}{\partial \delta_{k}}=-Q_{k}^{g u p f c}$

$H_{i j}^{g u p f c}=\frac{\partial P_{i}^{g u p f c}}{\partial \delta_{j}}=Q_{j}^{g u p f c}$

$H_{j i}^{g u p f c}=\frac{\partial P_{j}^{g u p f c}}{\partial \delta_{i}}=Q_{j}^{g u p f c}$

$H_{i k}^{g u p f c}=\frac{\partial P_{i}^{g u p f c}}{\partial \delta_{k}}=Q_{k}^{g u p f c}$

$H_{k i}^{g u p f c}=\frac{\partial P_{k}^{g u p f c}}{\partial \delta_{i}}=Q_{k}^{g u p f c}$

Similarly, the diagonal and off-diagonal elements of ' $N^{\text {gupfc, }}$ are 
$N_{i i}^{g u p f c}=\left|V_{i}\right| \frac{\partial P_{i}^{g u p f c}}{\partial V_{i}}=-P_{j}^{g u p f c}-P_{k}^{g u p f c}$

$N_{j j}^{g u p f c}=\left|V_{j}\right| \frac{\partial P_{j}^{g u p f c}}{\partial V_{j}}=P_{j}^{g u p f c}$

$N_{k k}^{g u p f c}=\left|V_{k}\right| \frac{\partial P_{k}^{g u p f c}}{\partial V_{k}}=P_{k}^{g u p f c}$

$N_{i j}^{g u p f c}=\left|V_{j}\right| \frac{\partial P_{i}^{g u p f c}}{\partial V_{j}}=-P_{j}^{g u p f c}$

$N_{j i}^{g u p f c}=\left|V_{i}\right| \frac{\partial P_{j}^{g u p f c}}{\partial V_{i}}=P_{j}^{g u p f c}$

$N_{i k}^{g u p f c}=\left|V_{k}\right| \frac{\partial P_{i}^{g u p f c}}{\partial V_{k}}=-P_{k}^{g u p f c}$

$N_{k i}^{g u p f c}=\left|V_{i}\right| \frac{\partial P_{k}^{g u p f c}}{\partial V_{i}}=P_{k}^{g u p f c}$

The diagonal and off-diagonal elements of ' $J^{g u p f c}$, are

$J_{i i}^{g u p f c}=\frac{\partial Q_{i}^{g u p f c}}{\partial \delta_{i}}=0$

$J_{j j}^{g u p f c}=\frac{\partial Q_{j}^{g u p f c}}{\partial \delta_{j}}=P_{j}^{g u p f c}$

$J_{k k}^{g u p f c}=\frac{\partial Q_{k}^{g u p f c}}{\partial \delta_{k}}=P_{k}^{g u p f c}$

$J_{i j}^{g u p f c}=\frac{\partial Q_{i}^{g u p f c}}{\partial \delta_{j}}=0$

$J_{j i}^{g u p f c}=\frac{\partial Q_{j}^{g u p f c}}{\partial \delta_{i}}=-P_{j}^{g u p f c}$

$J_{i k}^{g u p f c}=\frac{\partial Q_{i}^{g u p f c}}{\partial \delta_{k}}=0$

$J_{k i}^{g u p f c}=\frac{\partial Q_{k}^{g u p f c}}{\partial \delta_{i}}=-P_{k}^{g u p f c}$

Similarly, the diagonal and off-diagonal elements of ' gupfc, $^{\text {are }}$

$L_{i i}^{g u p f c}=\left|V_{i}\right| \frac{\partial Q_{i}^{g u p f c}}{\partial V_{i}}=2 Q_{i}^{g u p f c}$

$L_{j j}^{g u p f c}=\left|V_{j}\right| \frac{\partial Q_{j}^{g u p f c}}{\partial V_{j}}=Q_{j}^{g u p f c}$

$L_{k k}^{g u p f c}=\left|V_{k}\right| \frac{\partial Q_{k}^{g u p f c}}{\partial V_{k}}=Q_{k}^{g u p f c}$

$L_{i j}^{g u p f c}=\left|V_{j}\right| \frac{\partial Q_{i}^{g u p f c}}{\partial V_{j}}=0$

$L_{j i}^{g u p f c}=\left|V_{i}\right| \frac{\partial Q_{j}^{g u p f c}}{\partial V_{i}}=Q_{j}^{g u p f c}$

$L_{i k}^{g u p f c}=\left|V_{k}\right| \frac{\partial Q_{i}^{g u p f c}}{\partial V_{k}}=0$

$L_{k i}^{g u p f c}=\left|V_{i}\right| \frac{\partial Q_{k}^{g u p f c}}{\partial V_{i}}=Q_{k}^{g u p f c}$

\section{IV.OPTIMAL LOCATION STRATEGY}

From the careful review of the literature, it is identified that, FACTS controllers should be installed in an optimal location to maximize the effectiveness of the same. In this paper, an optimal location to install GUPFC is identified using contingency analysis. The conventional contingency analysis process through performance and severity indexes is used. In general, contingency analysis is a process of removing one of the transmission lines from a given network and identifying the total number of overloaded lines and their loadings. Using this, the performance index is calculated using

$$
\text { Performance index }\left(P I_{i}\right)=\frac{S_{i}}{S_{i}^{\text {max }}}
$$

Where, $S_{i}$ is the current apparent power flow through ith line, $S_{i}^{\text {max }}$ is the maximum MVA limit of ith line.
After calculating performance indexes of the over loaded lines under a contingency, severity index for each of the contingencies can be calculated using

$$
\text { Severity index }=\sum_{i=1}^{N L}\left(P I_{i}\right)^{2 m}
$$

Where, NL is the total number of over loaded lines, $\mathrm{m}$ is a constant considered to be 1 (one).

Based on the severity index values, rankings are assigned to each of the contingency. Finally, the power flows under rank-1 contingency are obtained. As GUPFC require two different transmission lines with a common bus. Hence, from the line flows information under rank-1 contingency, the lines which has highest power flow margin are identified to install GUPFC. To reduce the computational burden the following heuristic rules are formulated to identify an optimal location of this device.

1. GUPFC should be installed between two PQ buses only provided no shunt compensators are connected. 2. The tap changing transformer connected lines are not considered to install GUPFC.

\section{RESUltS AND ANALYSIS}

In this section, the proposed voltage source based power injection model of GUPFC is incorporated in a given power system using the procedure given in section-3 and the proposed methodology is tested on standard 5 bus and 14 bus test systems.

\section{A. Example-1}

IEEE-5 bus system with five buses and seven transmission lines is considered. Initially, contingency analysis is performed on this system and the obtained results are tabulated in Table.1. In this table, overloaded lines and their respective performance indexes for each of the contingency line are tabulated. The respective severity index values under each of the contingency are tabulated in Table.2. From this table, it is identified that, line connected between buses, 2 and 5 is the most critical one as it has highest severity index value when compared to other contingencies. The line flows under this critical contingency are tabulated in Table.3. From this table and the heuristic rules formulated in section.4, the optimal location to install GUPFC is identified between buses 4, 2 and 3 i.e. in lines 4 and 6 . The further analysis is assumed that, IPFC is connected in this location.

TABLE.1. RESULT OF CONTINGENCY ANALYSIS OF IEEE-5 BUS SYSTEM

\begin{tabular}{|c|c|c|c|c|c|}
\hline \multirow{2}{*}{$\begin{array}{c}\text { S. } \\
\text { No. }\end{array}$} & $\begin{array}{c}\text { Outage } \\
\text { line }\end{array}$ & $\begin{array}{c}\text { Over } \\
\text { loaded } \\
\text { lines }\end{array}$ & $\begin{array}{c}\text { Line flow } \\
\text { (MVA) }\end{array}$ & $\begin{array}{c}\text { Line } \\
\text { limit } \\
\text { (MVA) }\end{array}$ & PI \\
\hline 1 & $1-2$ & $1-3$ & 106.011 & 100 & 1.0601 \\
\cline { 3 - 6 } & & $3-4$ & 112.4979 & 100 & 1.125 \\
\hline 2 & $1-3$ & $1-2$ & 110.6946 & 100 & 1.1069 \\
\hline 3 & $2-3$ & - & - & - & - \\
\hline 4 & $2-4$ & $3-4$ & 100.4305 & 100 & 1.0043 \\
\hline 5 & $2-5$ & $3-4$ & 152.5254 & 100 & 1.5253 \\
\cline { 3 - 6 } & $4-5$ & 147.2209 & 100 & 1.4722 \\
\hline 6 & $3-4$ & $1-2$ & 110.5707 & 100 & 1.1057 \\
\hline 7 & $4-5$ & - & - & - & - \\
\hline
\end{tabular}

TABLE.2. SEVERITY INDEX VALUES OF IEEE-5 BUS SYSTEM 
INTERNATIONAL JOURNAL OF INNOVATIVE RESEARCH IN ELECTRICAL, ELECTRONICS, INSTRUMENTATION AND CONTROL ENGINEERING Vol. 2, Issue 10, October 2014

\begin{tabular}{|c|c|c|c|}
\hline S.No. & Outage line & Severity Index & Rank \\
\hline 1 & $1-2$ & 2.389411 & 2 \\
\hline 2 & $1-3$ & 1.225329 & 3 \\
\hline 3 & $2-3$ & - & 7 \\
\hline 4 & $2-4$ & 1.008628 & 5 \\
\hline 5 & $2-5$ & 4.493799 & 1 \\
\hline 6 & $3-4$ & 1.222587 & 4 \\
\hline 7 & $4-5$ & - & 6 \\
\hline
\end{tabular}
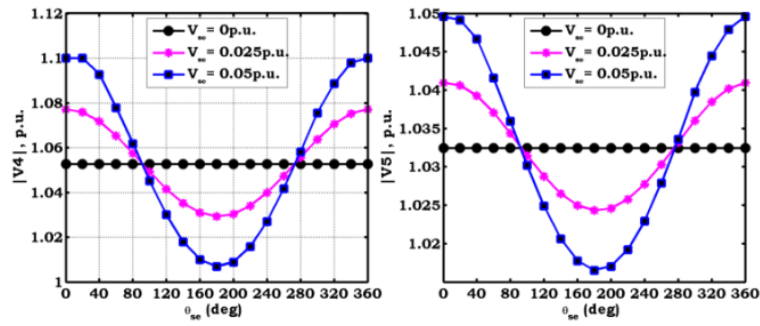

TABLE.3. POWER FLOWS AND MARGINS IN LINES UNDER RANK-1 CONTINGENCY OF IEEE-5 BUS SYSTEM

\begin{tabular}{|c|c|c|c|c|c|}
\hline $\begin{array}{c}\text { Line } \\
\text { No }\end{array}$ & $\begin{array}{c}\text { From } \\
\text { bus }\end{array}$ & $\begin{array}{c}\text { To } \\
\text { bus }\end{array}$ & $\begin{array}{c}\text { Line Flow } \\
\text { (MVA) }\end{array}$ & $\begin{array}{c}\text { Line Limit } \\
\text { (MVA) }\end{array}$ & $\begin{array}{c}\text { Margin } \\
\text { Limit } \\
\text { (MVA) }\end{array}$ \\
\hline 1 & 1 & 2 & 74.294 & 100 & 25.706 \\
\hline 2 & 1 & 3 & 58.24 & 100 & 41.76 \\
\hline 3 & 2 & 3 & 60.465 & 100 & 39.535 \\
\hline 4 & 2 & 4 & 87.083 & 100 & 12.917 \\
\hline 6 & 3 & 4 & 152.52 & 100 & -52.525 \\
\hline 7 & 4 & 5 & 147.22 & 100 & -47.221 \\
\hline
\end{tabular}

The further analysis is performed by varying GUPFC control parameters such as Vse from 0 p.u. to 0.05 p.u. in steps of 0.025 p.u. and voltage angle is varied from 0 deg to $360 \mathrm{deg}$ in steps of $20 \mathrm{deg}$. The consolidated variation of voltage magnitudes at buses by varying the GUPFC control parameters is shown in Fig.7. From this figure, it is identified that, major variation is observed at bus-4 as at this bus GUPFC sending end is connected. Similarly, the nest maximum variation is observed at bus-5, as this bus is connected nearer to device connected bus. The individual bus voltage magnitudes variation is shown in Fig.8. From this figure, it is observed that, voltage variation is increasing as Vse is increasing from 0 p.u. to 0.05 p.u. It is also observed that, minimum voltage magnitude is obtained when Vse is equal to 0.05 p.u. and $\theta$ se is at 180 deg and maximum voltage magnitude is obtained when Vse is at 0.05 p.u. and $\theta$ se is at $0 \mathrm{deg}$ or $360 \mathrm{deg}$.

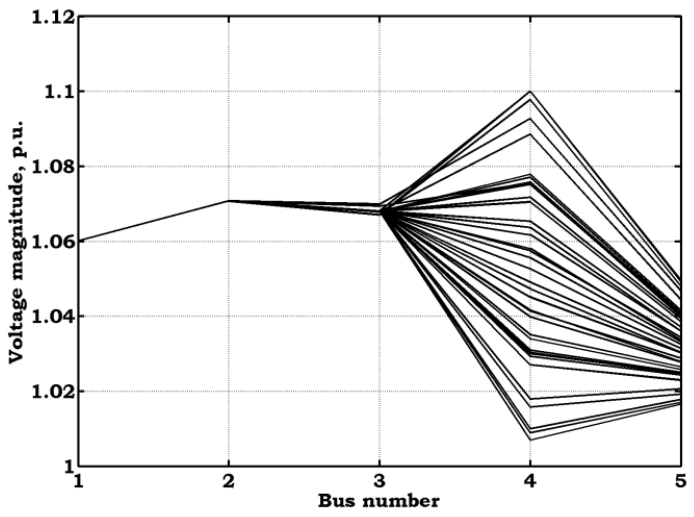

Fig.7. Consolidated variation of voltage magnitudes for IEEE-5 bus system

Fig.8. Individual variation of voltage magnitudes for IEEE-5 bus system

The consolidated variation of apparent power flow in lines by varying the GUPFC control parameters is shown in Fig.9. From this figure, it is identified that, due to variation of power flow in lines 4 and 6, major variation is observed in line 5. Similarly, the nest maximum variation is observed in line 7 , as this line is connected to device connected bus.

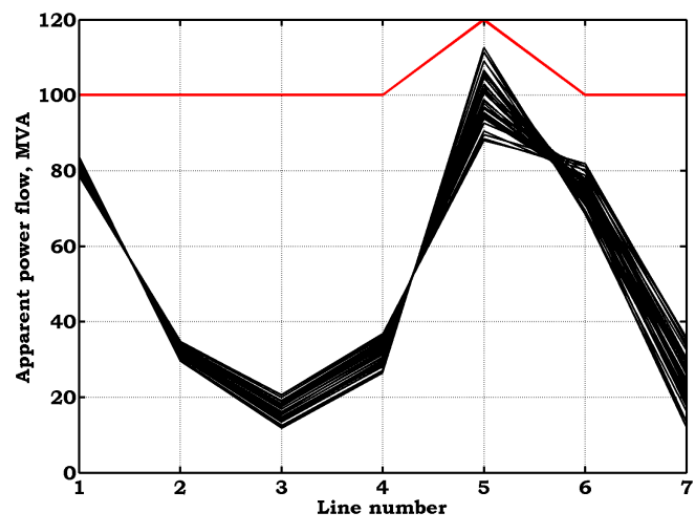

Fig.9. Consolidated variation of apparent power flows for IEEE-5 bus system

The variation of system active power losses by fixing Vse at constant value is shown in Fig.10. From this figure, it is observed that, active power loss variation is increasing as Vse is increasing from 0 p.u. to 0.05 p.u. It is also observed that, minimum losses are obtained when Vse is equal to 0.025 p.u. and $\theta$ se is at $60 \mathrm{deg}$ and maximum losses are obtained when Vse is at 0.05 p.u. and $\theta$ se is at $240 \mathrm{deg}$.

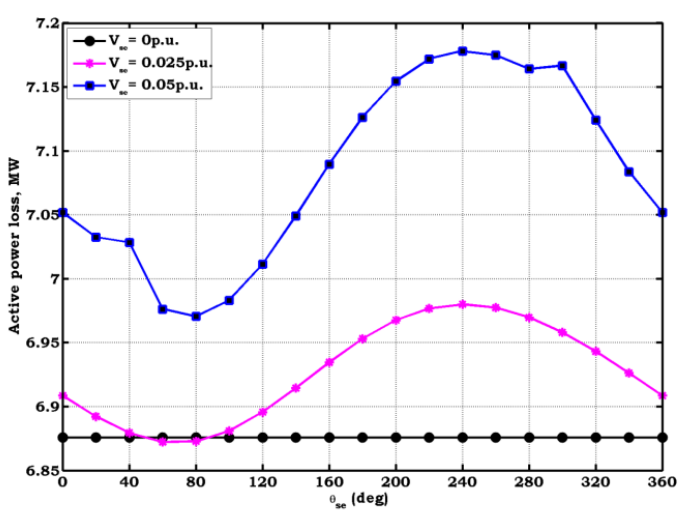

Fig.10. Variation of system active power losses when Vse is fixed for IEEE- 5 bus system 


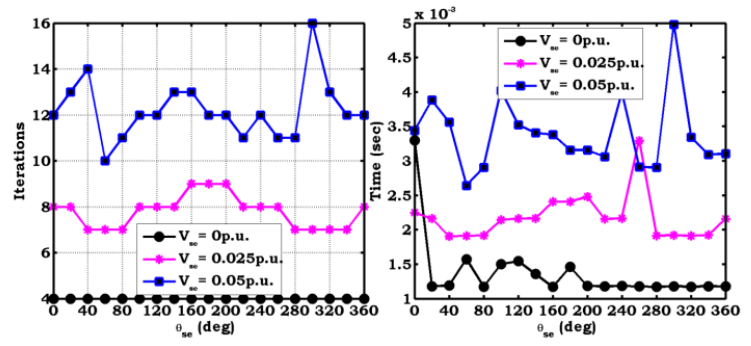

Fig.12. Variation of iterations and time taken for IEEE-5 bus system

\section{B. Example-2}

IEEE-14 bus system with twenty transmission lines is considered. Initially, contingency analysis is performed on this system and the obtained results are tabulated in Table.4. In this table, overloaded lines and their respective performance indexes for each of the contingency line are tabulated. The respective severity index values under each of the contingency are tabulated in Table.5. From this table, it is identified that, line connected between buses, 4 and 5 is the most critical one as it has highest severity index value when compared to other contingencies. The line flows under this critical contingency are tabulated in Table.6. From this table and the heuristic rules formulated in section.4, the optimal location to install GUPFC is identified between buses 4, 2 and 5 i.e. in lines 3 and 6 . The further analysis is assumed that, IPFC is connected in this location.

INTERNATIONAL JOURNAL OF INNOVATIVE RESEARCH IN ELECTF
Vol. 2, Issue 10, October 2014

INTERNATIONAL JOURNAL OF INNOVATIVE RESEARCH IN ELECTF
Vol. 2, Issue 10, October 2014

INTERNATIONAL JOURNAL OF INNOVATIVE RESEARCH IN ELECTF
Vol. 2, Issue 10, October 2014

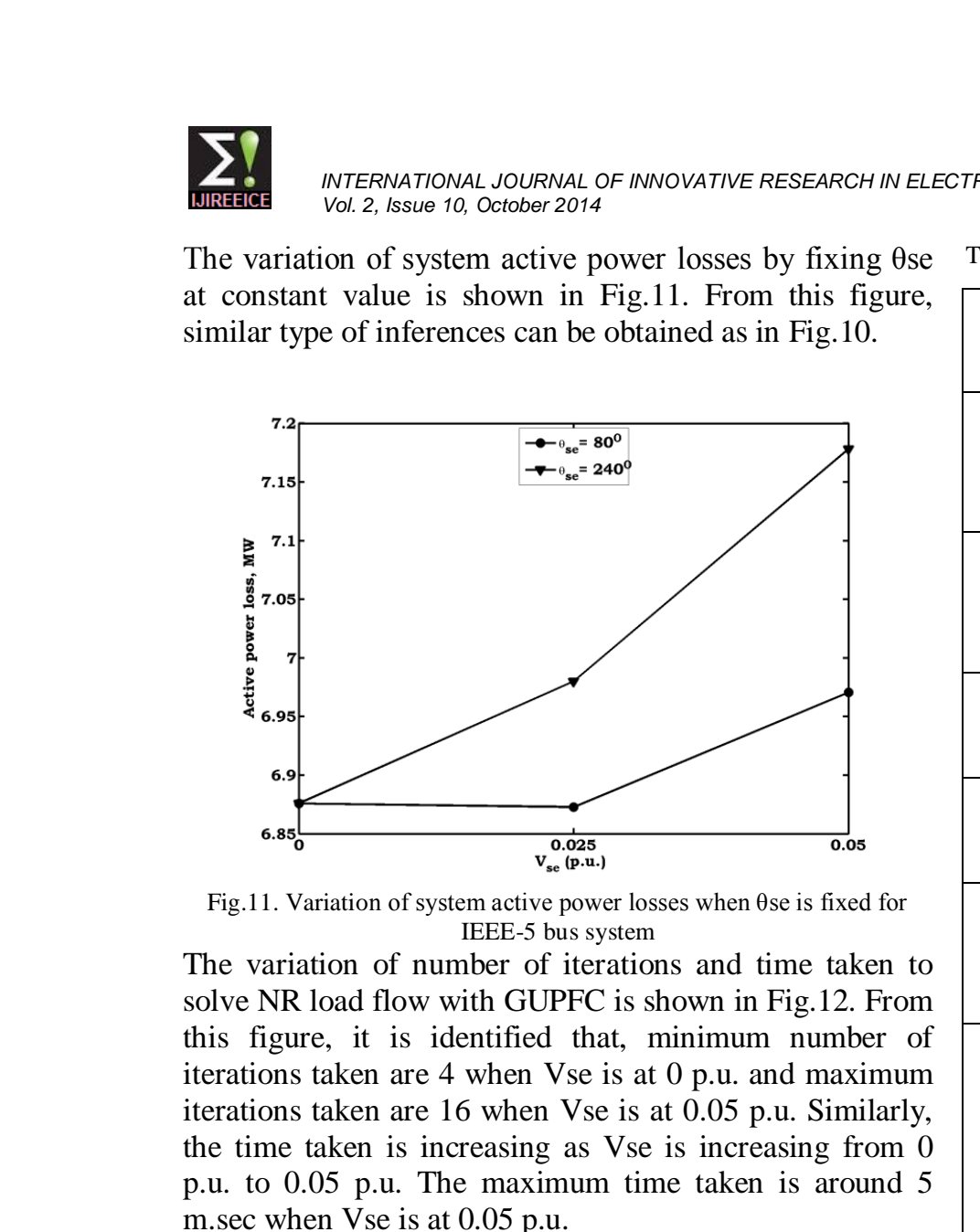

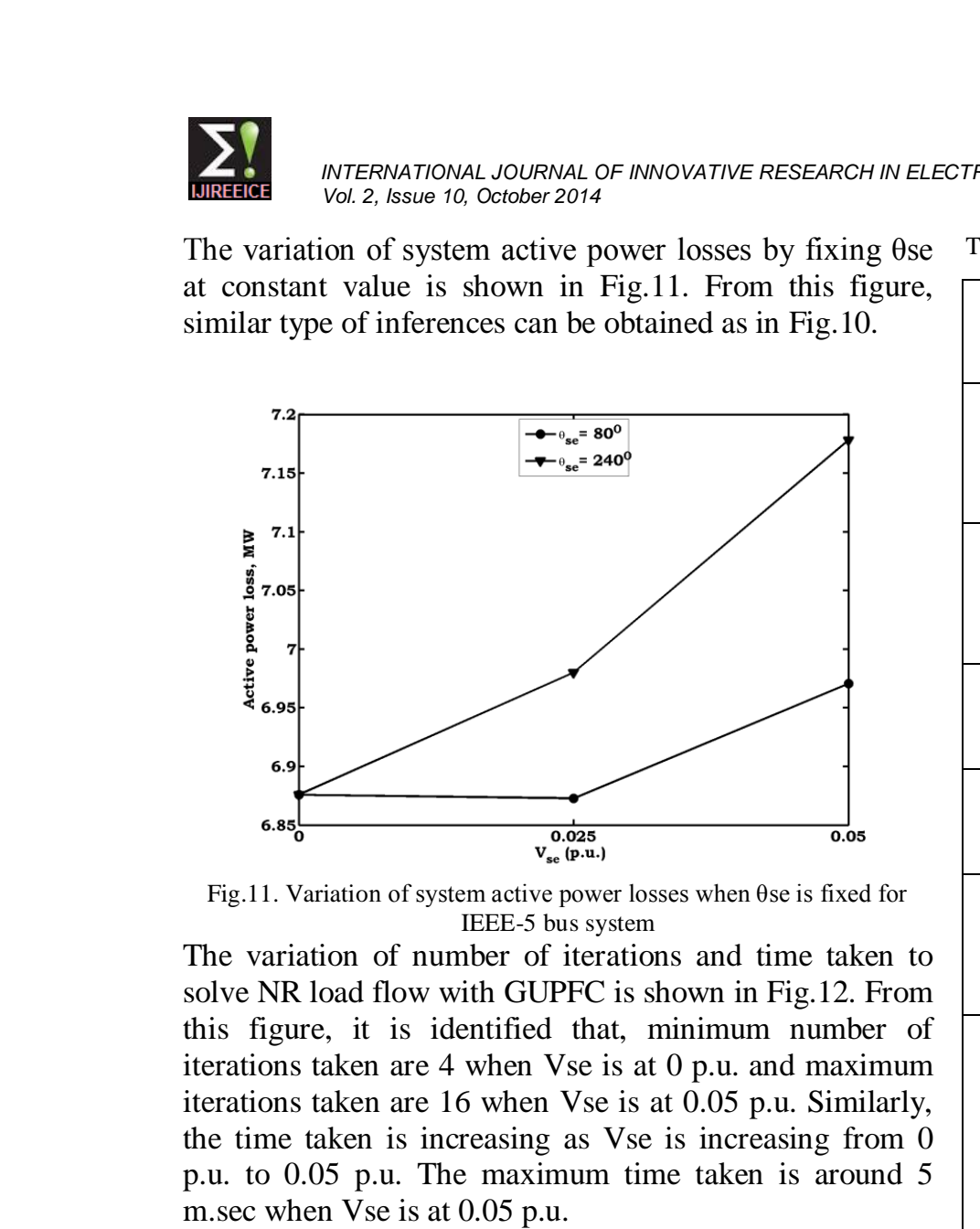

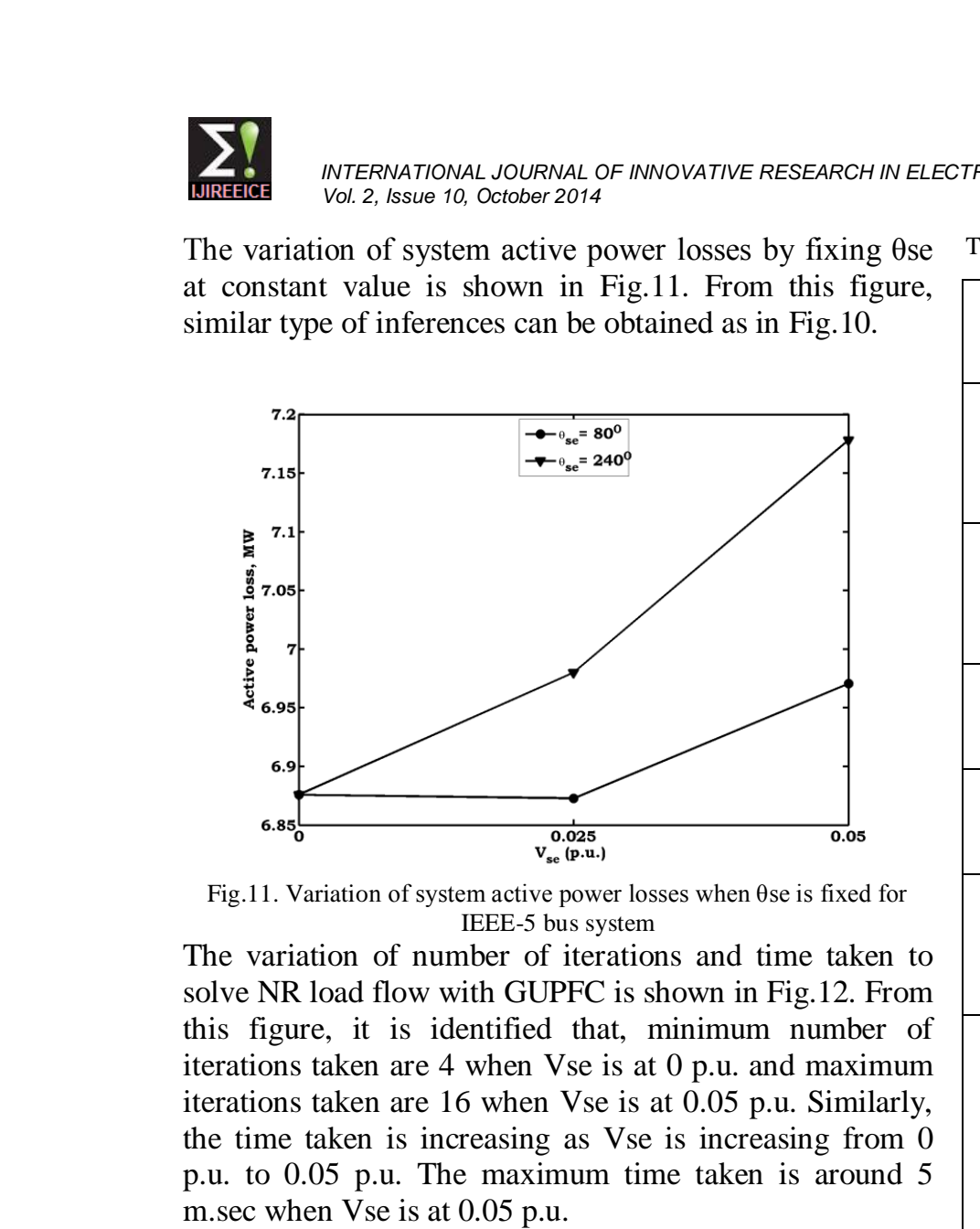

INTERNATIONAL JOURNAL OF INNOVATIVE RESEARCH IN ELECTF
Vol. 2, Issue 10, October 2014

INTERNATIONAL JOURNAL OF INNOVATIVE RESEARCH IN ELECTF
Vol. 2, Issue 10, October 2014

INTERNATIONAL JOURNAL OF INNOVATIVE RESEARCH IN ELECTF
Vol. 2, Issue 10, October 2014

INTERNATIONAL JOURNAL OF INNOVATIVE RESEARCH IN ELECTF
Vol. 2, Issue 10, October 2014

INTERNATIONAL JOURNAL OF INNOVATIVE RESEARCH IN ELECTF
Vol. 2, Issue 10, October 2014

INTERNATIONAL JOURNAL OF INNOVATIVE RESEARCH IN ELECTF
Vol. 2, Issue 10, October 2014

INTERNATIONAL JOURNAL OF INNOVATIVE RESEARCH IN ELECTF
Vol. 2, Issue 10, October 2014

INTERNATIONAL JOURNAL OF INNOVATIVE RESEARCH IN ELECTF
Vol. 2, Issue 10, October 2014

TABLE.4. RESULT OF CONTINGENCY ANALYSIS OF IEEE-14 BUS SYSTEM

\author{
s.
}

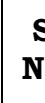

\begin{tabular}{|c|c|c|c|}
$\begin{array}{c}\text { Over } \\
\text { loaded } \\
\text { lines }\end{array}$ & $\begin{array}{c}\text { Line } \\
\text { flow } \\
\text { (MVA) }\end{array}$ & $\begin{array}{c}\text { Line } \\
\text { limit } \\
\text { (MVA) }\end{array}$ & PI \\
\hline $1-2$ & 241.111 & 150 & 1.607 \\
\hline $2-3$ & 87.141 & 85 & 1.025 \\
\hline
\end{tabular}

\begin{tabular}{|c|c|c|c|c|c|}
\multirow{3}{*}{1} & \multirow{2}{*}{$1-5$} & $2-3$ & 87.141 & 85 & 1.025 \\
\cline { 3 - 6 } & & $4-7$ & 31.79 & 30 & 1.06 \\
\cline { 3 - 6 } & & $7-9$ & 29.799 & 29 & 1.028 \\
\hline \multirow{3}{*}{2} & \multirow{3}{*}{$2-3$} & $1-5$ & 95.438 & 85 & 1.123 \\
\cline { 3 - 6 } & & $2-4$ & 93.614 & 85 & 1.101 \\
\cline { 3 - 6 } & & $3-4$ & 96.512 & 85 & 1.135 \\
\hline
\end{tabular}

\begin{tabular}{|c|c|c|c|c|c|}
\hline \multirow{3}{*}{2} & $2-3$ & $2-4$ & 93.614 & 85 & 1.101 \\
\cline { 3 - 6 } & & $3-4$ & 96.512 & 85 & 1.135 \\
\cline { 3 - 6 } & $5-6$ & 47.851 & 45 & 1.063 \\
\hline \multirow{3}{*}{3} & \multirow{3}{*}{$2-4$} & $1-5$ & 92.291 & 85 & 1.086 \\
\cline { 3 - 6 } & & $2-3$ & 90.22 & 85 & 1.061 \\
\cline { 3 - 6 } & & $5-6$ & 47.769 & 45 & 1.062 \\
\hline
\end{tabular}

\begin{tabular}{|c|c|c|c|c|c|}
\cline { 3 - 6 } 4 & $5-6$ & 47.769 & 45 & 1.062 \\
\hline \multirow{3}{*}{4} & \multirow{3}{*}{$2-5$} & $1-5$ & 91.529 & 85 & 1.077 \\
\cline { 3 - 6 } & & $4-7$ & 30.773 & 30 & 1.026 \\
\cline { 3 - 6 } & $7-9$ & 29.536 & 29 & 1.019 \\
\hline \multirow{3}{*}{5} & \multirow{3}{*}{$3-4$} & $1-2$ & 163.933 & 150 & 1.093 \\
\cline { 3 - 6 } & & $2-3$ & 98.386 & 85 & 1.158 \\
\cline { 3 - 6 } & & $5-6$ & 45.423 & 45 & 1.009 \\
\hline
\end{tabular}

\footnotetext{
.

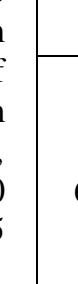

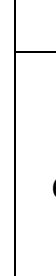

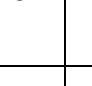

\begin{tabular}{|c|c|c|c|c|}
\hline & $3-0$ & & 40 & \\
\hline & $7-9$ & 29.323 & 29 & 1.011 \\
\hline \multirow{7}{*}{$4-5$} & $1-2$ & 179.437 & 150 & 1.196 \\
\hline & $2-3$ & 89.145 & 85 & 1.049 \\
\hline & $2-4$ & 89.235 & 85 & 1.05 \\
\hline & $5-6$ & 62.118 & 45 & 1.38 \\
\hline & $6-11$ & 17.416 & 14 & 1.244 \\
\hline & $6-13$ & 23.768 & 22 & 1.08 \\
\hline & $10-11$ & 13.444 & 12 & 1.12 \\
\hline \multirow{3}{*}{$6-11$} & $1-2$ & 158.605 & 150 & 1.057 \\
\hline & $4-7$ & 31.819 & 30 & 1.061 \\
\hline & $7-9$ & 32.583 & 29 & 1.124 \\
\hline \multirow{4}{*}{$6-12$} & $1-2$ & 158.363 & 150 & 1.056 \\
\hline & $5-6$ & 45.631 & 45 & 1.014 \\
\hline & $6-13$ & 26.573 & 22 & 1.208 \\
\hline & $7-9$ & 29.305 & 29 & 1.011 \\
\hline \multirow{4}{*}{$6-13$} & $1-2$ & 159.057 & 150 & 1.06 \\
\hline & $4-7$ & 31.145 & 30 & 1.038 \\
\hline & $7-9$ & 31.958 & 29 & 1.102 \\
\hline & $12-13$ & 13.71 & 12 & 1.143 \\
\hline \multirow{5}{*}{$7-9$} & $1-2$ & 157.537 & 150 & 1.05 \\
\hline & $5-6$ & 60.712 & 45 & 1.349 \\
\hline & $6-11$ & 17.632 & 14 & 1.259 \\
\hline & $6-13$ & 24.157 & 22 & 1.098 \\
\hline & $10-11$ & 13.088 & 12 & 1.091 \\
\hline \multirow{3}{*}{$9-10$} & $1-2$ & 158.012 & 150 & 1.053 \\
\hline & $5-6$ & 49.24 & 45 & 1.094 \\
\hline & $6-11$ & 15.191 & 14 & 1.085 \\
\hline \multirow{4}{*}{$9-14$} & $1-2$ & 158.148 & 150 & 1.054 \\
\hline & $5-6$ & 51.102 & 45 & 1.136 \\
\hline & $6-13$ & 27.94 & 22 & 1.27 \\
\hline & $13-14$ & 16.409 & 12 & 1.367 \\
\hline \multirow{3}{*}{$10-11$} & $1-2$ & 158.364 & 150 & 1.056 \\
\hline & $4-7$ & 30.65 & 30 & 1.022 \\
\hline & $7-9$ & 30.752 & 29 & 1.06 \\
\hline \multirow{2}{*}{$12-13$} & $1-2$ & 158.176 & 150 & 1.055 \\
\hline & $5-6$ & 45.911 & 45 & 1.02 \\
\hline \multirow{3}{*}{$13-14$} & $1-2$ & 158.465 & 150 & 1.056 \\
\hline & 4-7 & 30.98 & 30 & 1.033 \\
\hline & $7-9$ & 31.207 & 29 & 1.076 \\
\hline
\end{tabular}


TABLE.5. SEVERITY INDEX VALUES OF IEEE-14 BUS SYSTEM

\begin{tabular}{|c|c|c|c|}
\hline S.No. & Outage line & Severity Index & Rank \\
\hline 1 & $1-5$ & 5.8135 & 4 \\
\hline 2 & $2-3$ & 4.8936 & 5 \\
\hline 3 & $2-4$ & 3.4324 & 11 \\
\hline 4 & $2-5$ & 3.2491 & 14 \\
\hline 5 & $3-4$ & 4.5755 & 8 \\
\hline 6 & $4-5$ & 9.5083 & 1 \\
\hline 7 & $6-11$ & 3.5054 & 9 \\
\hline 8 & $6-12$ & 4.6229 & 7 \\
\hline 9 & $6-13$ & 4.722 & 6 \\
\hline 10 & $7-9$ & 6.9047 & 2 \\
\hline 11 & $9-10$ & 3.4844 & 10 \\
\hline 12 & $9-14$ & 5.8839 & 3 \\
\hline 13 & $10-11$ & 3.2829 & 13 \\
\hline 14 & $12-13$ & 2.1529 & 15 \\
\hline 15 & $13-14$ & 3.3404 & 12 \\
\hline
\end{tabular}

TABLE.6. POWER FLOWS AND MARGINS IN LINES UNDER RANK-1 CONTINGENCY OF IEEE-14 BUS SYSTEM

\begin{tabular}{|c|c|c|c|c|c|}
\hline $\begin{array}{l}\text { Lin } \\
\text { e } \\
\text { No }\end{array}$ & $\begin{array}{c}\text { Fro } \\
\text { m } \\
\text { bus }\end{array}$ & $\begin{array}{c}\text { To } \\
\text { bu } \\
\text { s }\end{array}$ & $\begin{array}{c}\text { Line } \\
\text { Flow } \\
\text { (MVA) }\end{array}$ & $\begin{array}{c}\text { Line } \\
\text { Limit } \\
\text { (MVA }\end{array}$ & $\begin{array}{c}\text { Margin } \\
\text { Limit } \\
\text { (MVA) }\end{array}$ \\
\hline 1 & 1 & 2 & 163.932 & 150 & -13.9328 \\
\hline 2 & 1 & 5 & 70.2651 & 85 & 14.7349 \\
\hline 3 & 2 & 3 & 98.386 & 85 & -13.386 \\
\hline 4 & 2 & 4 & $\begin{array}{c}44.727 \\
7\end{array}$ & 85 & 40.2723 \\
\hline 5 & 2 & 5 & 33.1436 & 85 & 51.8564 \\
\hline 7 & 4 & 5 & $\begin{array}{c}50.502 \\
7\end{array}$ & 150 & 99.4973 \\
\hline 8 & 4 & 7 & 29.7489 & 30 & 0.2511 \\
\hline 9 & 4 & 9 & 16.3438 & 32 & 15.6562 \\
\hline 10 & 5 & 6 & 45.4232 & 45 & -0.4232 \\
\hline 11 & 6 & 11 & 7.9251 & 14 & 6.0749 \\
\hline 12 & 6 & 12 & 8.1479 & 32 & 23.8521 \\
\hline 13 & 6 & 13 & 19.0136 & 22 & 2.9864 \\
\hline 14 & 7 & 8 & 16.9261 & 32 & 15.0739 \\
\hline 15 & 7 & 9 & 29.3233 & 29 & -0.3233 \\
\hline 16 & 9 & 10 & 6.8729 & 32 & 25.1271 \\
\hline 17 & 9 & 14 & 10.2731 & 18 & 7.7269 \\
\hline 18 & 10 & 11 & 3.8713 & 12 & 8.1287 \\
\hline 19 & 12 & 13 & 1.7611 & 12 & 10.2389 \\
\hline 20 & 13 & 14 & 5.7232 & 12 & 6.2768 \\
\hline
\end{tabular}

To extend the effectiveness of the proposed GUPFC modeling, here five combinations of GUPFC control parameters are considered.

Case-1: Vseij $=0.02$; Thseij $=72$; Vseik $=0.1$; Thseik $=360$

Case-2: Vseij=0.04; Thseij=144; Vseik=0.08; Thseik=288

Case-3: Vseij $=0.06$; Thseij $=216$; Vseik $=0.06$; Thseik $=216$

Case-4: Vseij=0.08; Thseij=288; Vseik $=0.04$; Thseik $=144$

Case-5: Vseij=0.1; Thseij=360; Vseik=0.02; Thseik=72

The variation of bus voltage magnitudes for these five cases is shown in Fig.13. From this figure, it is observed that, bus-4 has major variation when compared to other buses, because GUPFC sending end is connected at this bus.

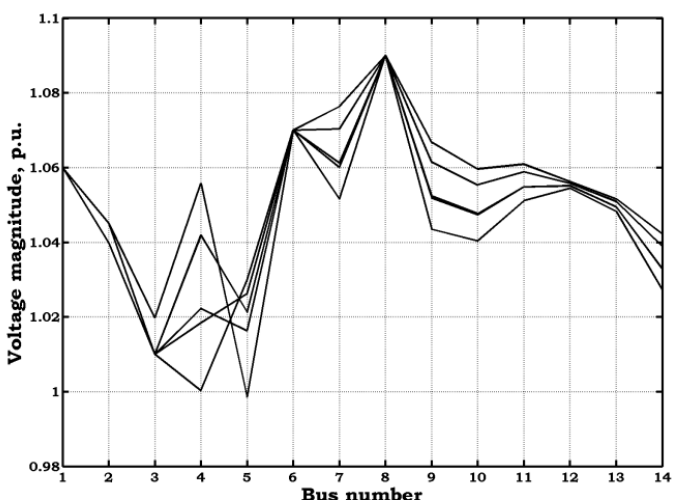

Fig.13. Variation of bus voltage magnitudes in five cases for IEEE-14 bus system

The variation of apparent power flow in transmission lines for these five cases is shown in Fig.14. Due to variation in device connected lines ( 3 and 6 ), maximum variation is observed in line 7 , as it is connected to device connected buses. It is also observed that, because of this device, in most of the transmission lines, apparent power is flowing nearer to its thermal limit.

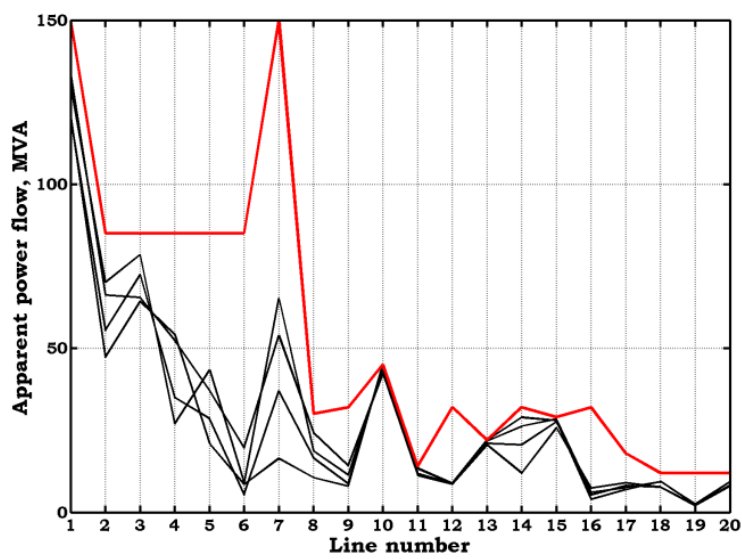

Fig.14. Variation of line apparent power flows in five cases for IEEE-14 bus system

The variation of active power losses for the five cases is shown in Fig.15. From this figure, it is observed that, minimum losses are obtained in case- 2 and maximum losses are obtained in case- 5 .

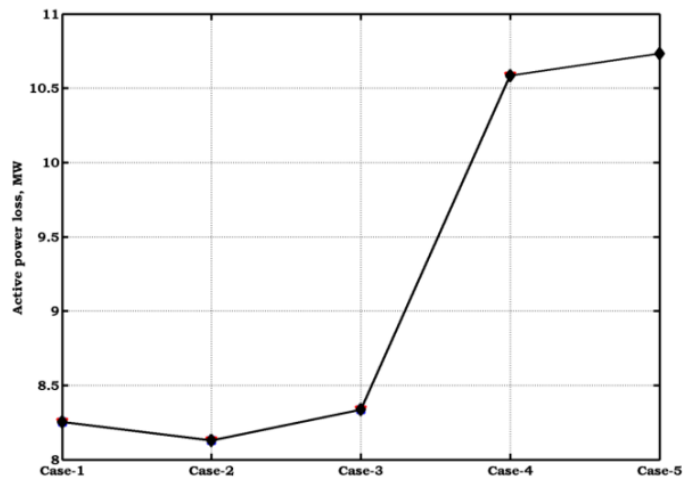

Fig.15. Variation of system active power losses in five cases for IEEE-14 bus system 


\section{CONCLUSION}

In this paper, voltage source based power injection model of GUPFC has been presented. Using this, the effect of this device is analyzed on system parameters. An optimal location strategy based on contingency analysis through performance and severity indexes has been presented. The system control parameters such as voltage magnitudes at buses, apparent power flows in transmission lines, and system active power losses has been analyzed by varying the device control parameters. The proposed methodology has been tested on standard IEEE-5 bus and IEEE-14 bus test systems has been analyzed.

\section{REFERENCES}

[1] L. Gyugyi.,"Unified power flow control concept for Flexible AC Transmission systems", IEE Proceedings on Generation, Transmission and Distribution, 1992, Vol 139, No. 4, pp. 323-331.

[2] L Gyugyi, C D Schauder, et al.,"The Unified Power Flow Controller:A new appraoch to power transmission control", IEEE Transactions on Power Delivery, 1995, Vol. 10, No. 2, pp. 10851097

[3] N.G. Hingorani.,"Flexible AC transmission", IEEE Spectrum 30,1993,pp. 40-45.

[4] Xiao-Ping Zhang, Christian Rehtanz, Bikash Pal.,"Flexible AC Transmission Systems: Modelling and Control (Power Systems)",Springer (March 2006)., ISBN:3540306064.

[5] L. Gyugyi.,"Unified power flow control concept for Flexible AC Transmission systems", IEE Proceedings on Generation, Transmission and Distribution, 1992, Vol 139, No. 4, pp. 323-331.

[6] L Gyugyi, C D Schauder, et al.,"The Unified Power Flow Controller:A new appraoch to power transmission control", IEEE Transactions on Power Delivery, 1995, Vol. 10, No. 2, pp. 10851097.

[7] C R Fuerte Esquivel, E Acha.,"Unified power flow controller:a critical comparison of Newton-Raphson UPFC algorithms in power flow studies", IEE Proceedings on Generation, Transmission and Distribution, 1997, Vol 144, No. 5, pp. 437-444.

[8] M Noroozian, L Angquist, M Ghandhari, G Anderson.,"Use of UPFC for optimal power flow control", IEEE Transactions on Power Delivery, 1997, Vol. 12, No. 4, pp.1629-1634.

[9] C R Fuerte Esquivel, E Acha, H Ambriz Perez.,"A Comprehensice Newton-Raphson UPFC Model for the Quadratic Power Flow Solution of Practical Power Networks", IEEE Transactions on power systems, 2000, Vol. 15, No. 1, pp. 102-109.

[10] Wanliang Fang, H W Ngan.,"A robust load flow technique for use in power system with unified power flow controller", Electric Power Systems Reseach., 2000, Vol 53, pp. 181-186.

[11] C D Schauder, L Gyugyi, M R Lund, et al.,"Operation of the Unified Power Flow Controller (UPFC) under practical constraints", IEEE Transactions on Power Delivery, 1998, Vol 13, No. 2, pp. 630-639.

[12] K S Verma, S N Singh, H O Gupta.,"Location of unified power flow controller for congestion management", Electrical Power and Energy Systems, 2001, Vol. 58, pp. 89-86.

[13] D Z Fang, Z Fang, H F Wang.,"Application of the injection modeling approach to power flow analysis for systems with unified power flow controller", Electrical Power and Energy Systems, 2001, Vol. 23, pp. 421-425.

[14] A. L Abbate, M. Trovato, C. Becker, E. Handschin.,"Advanced Steady-State Model of UPFC for Power System Studies", Power Engineering Society Summer Meeting (IEEE), 2002, Vol. 1, pp 449-454.

[15] M H Haque, C M Yam.,"A simple method of solving the controlled load flow problem of a power system in the presence of UPFC", Electric Power Systems Reseach., 2003, Vol 65, pp. 55-62.

[16] Mehmet Tumay, A M Vural, K L Lo.,"The effect of unified power flow controller location in power systems", Elecrical Power and Energy Systems, 2004, Vol. 26, pp. 561-569.

[17] A Mete Vural, Mehmet Tumay.,"Mathematical modeling and analysis of a unified power flow controller: A comparision of two appraoches in power flow studies and effects of UPFC location", Electrical Power and Energy Systems, 2007, Vol. 29, pp. 617-629. Copyright to IJIREEICE
[18] Suman Bhowmick, Biswarup Das, Narendra Kumar.,"An Indirect UPFC Model to Enhance Reusability of Newton Power Flow Codes", IEEE Transactions on Power Delivery, 2008, Vol. 23, No. 4, pp. 2079-2088

19] B. Fardanesh, B. Shperling, E. Uzunovic, S.Zelingher.,"MultiConverter FACTS Devices:The Generalized Unified Power Flow Controller (GUPFC)", Power Engineering Society Summer Meeting, 2000. IEEE., Vol. 2, pp. 1020-1025.

[20] J G Singh, P Tripathy, S N Singh, C Srivastava.,"Development of a fuzzy rule based generalized unified power flow controller", European Transactions on Electrical Power, 2009, Vol.19, pp. 702717.

[21] Xiao-Ping Zhang, Edmund Handschin, Maojun Mike Yao.,"Modeling of the Generalized Unified Power Flow Controller (GUPFC) in a Nonlinear Interior Point OPF", IEEE Transactions on Power Systems, Vol 16, No. 3, 2001, pp 367-373.

[22] Rakhmad Syafutra Lubis, Sasongko Pramono Hadi, Tumiran.,"Modeling of the Generalized Unified Power Flow Controller for Optimal Power Flow", ICEEI (IEEE), 2011, pp. 1-6.

[23] X P Zhang.,"Modelling of the interline power flow controller and the generalised unified power flow controller in Newton power flow", IEE Proceedings on Generation, Transmission and Distribution, 2003, Vol 150, No. 3, pp. 268-274.

[24] Rakhmad Syafutra Lubis., "Modeling and Simulation of Generalized Unified Power Flow Controller (GUPFC)", 2nd International Conference on ICICI-BME (IEEE), 2011., pp. 207-213.

[25] R Thirumalaivasan, Nagesh Prabhu, M Janaki, D P Kothari.,"Analysis of subsynchronous resonance with generalized unified power flow controller", Electrical Power and Energy Systems, 2013, Vol.53, pp. 623-631.

\section{BIOGRAPHY}

Chintalapudi V Suresh is currently pursuing Ph.D. in the department of Electrical and Electronics Engineering, University College of Engineering Kakinada, Jawaharlal Nehru Technological University Kakinada, Kakinada, A.P., India.

His interest includes, Computer Applications in Power Systems, Optimization Techniques, FACTS, Power System Analysis including FACTS devices and Power System Operation and Control.

Sirigiri Sivanagaraju is Professor in the department of Electrical and Electronics Engineering, University College of Engineering Kakinada, Jawaharlal Nehru Technological University Kakinada, Kakinada, A.P., India. He completed his Master's degree from Indian Institute of Technology, Khargpur, India, in electrical power systems. He completed his doctoral program from Jawaharlal Nehru Technological University Hyderabad, Andhra Pradesh, India.

His interests includes, FACTS Controllers, Electrical Distribution System Automation, Optimization Techniques, Voltage Stability, Power System Analysis, and Power System Operation and Control. 